\title{
Exploring Lebanese Cultural Dimensions Affecting Levels Of University HR Performance
}

\author{
Bassam G. Macky ${ }^{1}$, Ale J. Hejase ${ }^{2}$, Hussin J. Hejase ${ }^{3^{*}}$ \\ Islamic University of Lebanon, Beirut, Lebanon ${ }^{1}$, Lebanese American University, Beirut, Lebanon ${ }^{2}$, \\ American University of Science and Technology, Beirut, Lebanon ${ }^{3}$

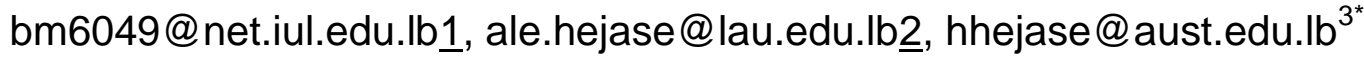

\begin{abstract}
Maximizing performance is considered an ultimate goal at business and country levels. Consequently human talent, viewed as an essential organizational asset, is sought after to fit organizational needs to build best practices in performance. However, researchers have found that culture plays a vital role and isconsidered the most dominant and life-long affecting variable on human outcomes. Although culture-oriented applications is becoming a management trend in developed countries, very little or no research is focused on cultural backgroundofhuman resources performance in Lebanon. This paper sheds light on the aforementioned issue and analyzes current cultural attitudes as gleaned from a sample of universities' HR in Lebanon. The methodology used is quantitative descriptive. The research tool is a closedend, five-scale Likert-type questionnairedesignedbased on Hofstede and GLOBE cultural constructs, and used for surveying purposes. The questionnaire is answered by universities' HR represented by university staff and instructors selected from a number of Lebanese universities. Questionnaire subscales have been validated using reliability test and factor analysis' Varimax rotation method. Hypotheses are tested by computing score means and standard deviations. Research findings serve as recommendations to guide managers and officials to set policies that sustain positive attitudes and isolate negative ones with an aim to maximize HR performance.
\end{abstract}

KEYWORDS- Lebanon, human resources, performance, societal culture, GLOBE, Hofstede.

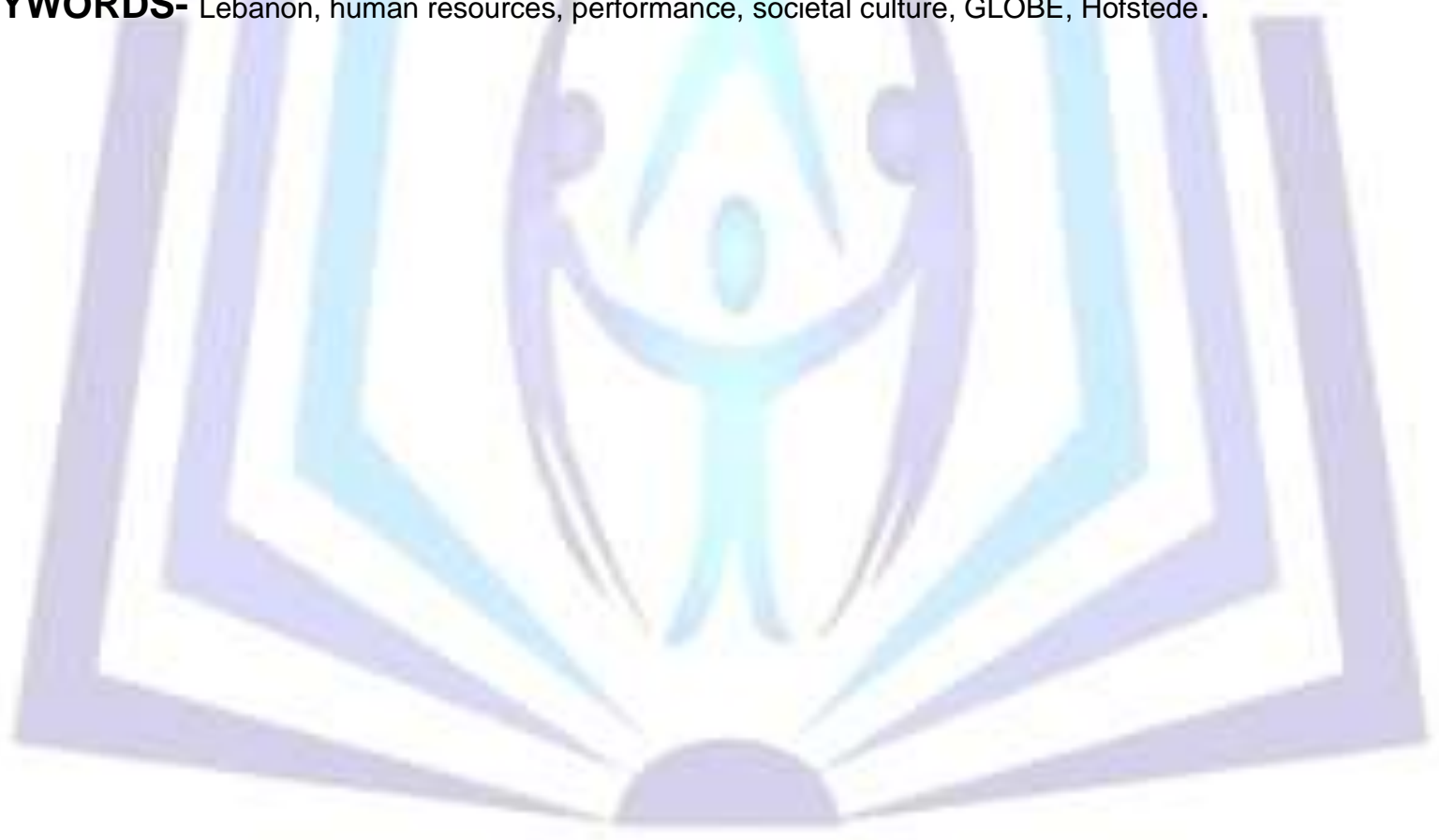

\section{Council for Innovative Research}

Peer Review Research Publishing System

Journal: International Journal of Management \& Information Technology

Vol. 10 No. 3

editorsijmit@gmail.com

www.ijmit.com/ojs 


\section{INTRODUCTION}

At Davos Forum, world leaders of different sectors concurred on moving from capitalism to talentism and networked innovation;capital is being superseded by creativity and the ability to innovate - and therefore by human talents (Schwab, 2012, p. 18/3).Talentism expresses itself in performing workforce. As defined by the Chartered Institute of Personnel and Development (CIPD),"talent is a characteristic of those individuals who can make a difference to organizational performance, either through their immediate contribution, or in the longer term, by demonstrating the highest levels of potentials"(Armstrong, 2009, p. 680).

\section{* Correspondence author}

Attracting talented workforce constitute a global challenge in the coming times at two levels: management and human resources. On one hand, 35\% of employers worldwide are experiencing difficulty filling jobs due to lack of available talent (Manpower Group, 2013, p. 2), while on the other hand,almost202 millionpeople are unemployed (International Labour Organization, 2014, p. 11). Therefore, the problem is not a lack of people who could, theoretically, be hired but rather the mismatch between skills people have and skills employers need (Ashford, 2014, p. 9).

Locally, much of the demand for higher skills has been addressed at an organizational level through a combination of strategies encompassing retraining, recruiting from abroad, offshoring, and out-sourcing (Mankin, 2009, pp. 15-26). However, regionally and internationally, the factor which may be in favor of many nations is the existing human ecosystem that presentsgreat opportunities for talent through a worldwide network that has few limits (Ashford, 2014, p. 11).

Only high performing HR would put the aforementioned human ecosystem potential in effect. A purposeful research aims to project this global trend on national levelso as to have the ability to think globally,though acting locally(Mankin, 2009, p. 15). The rapidly evolving global marketplace for labor has made the need for a national human capital development strategy even more critical;however, the absence of long-termhuman capital strategy planning can perpetuate continued wasted potentials in a country's population and losses in the nation's growth and productivity (Jacobs, 2013, p. 1, 27). The national human capital development strategy is much attributed to developed countries; therefore, the researchers may wonder about the applicability of such concept in Lebanon.Consequently, adapting to employment global trends urges research to asses HR position in Lebanon. Talents are vital for national economy, but are also a target of international and multinational corporations. For example, Lebanese workforce has ever been considered driver of economics in many countries over the world, especially in Brazil, many African and Arab states, that is, where the Lebanese diaspora resides.

Long-term planning trends that respond to rapidly changing conditions or requirements of developmentsare sensitive to national culture. If at organizational level, culture helps sustain its brand, uniqueness, responsiveness and competitiveness for longest possible period, how would culture be at national level? High performance national culture will be more dynamic and better responsive to every coming challenge.

This paper will review concepts of HR performance, national (country) culture and their correlations; shed light on key cultural facts (Performance Orientation, Future Orientation, Collectivism and Power Distance) of Lebanon; develop hypotheses; and, finally investigate Lebanese HR attitudes regarding the aforementioned cultural facts. Time limitations and prioritization have made these four issues draw the researchers' interest.

\section{RELATED LITERATURE REVIEW}

According to Elsaid and Elsaid (2012), literature review shows that there is little research published in and on the Arab countries as to both national societal culture (p. 3) and comparative cross-cultural studies (Sidani\& Gardner, 2000, p. 598). Attempts to replicate, validate, or expand on Hofstede's work on national cultures in the Middle East have been virtually nonexistent since his initial study (Robertson, Al-Khatib, \& Al-Habib, 2002, p. 586). Ralston, Egri, Riddle, Butt, Dalgic, \& Brock(2012, pp. 480-481) concluded that scant research has been published on the Middle Eastregion in the business literature quoting other researchers for example, Ali (1995), Hofstede (2001), and Robertson, Al-Khatib, Al-Habib, \&Lanoue (2001) with the primary focus being the cultural values homogeneity within the Arab or Arabic subset of countries.Scholarly understanding of the business values, norms, and behaviors subscribed to in this region have been murky at best (Ralston et al., 2012, p. 481).

\subsection{HR and Performance}

Organizations continuously seek sustained high performance;they do thisthrough the systems of work they adopt, but these systems are managed and operated by people. Therefore, high-performance work is about improving performance throughpeople(Armstrong, 2009, 258).

"Human Resources"is a contemporary concept depicting the workforce. Initially HR stood for personnel and employees. However, now-a-days, HR represents people who work within an organized entity. With time, during the second half of the twentieth century, the complexity of production has grantedthe workforce higher attention and consideration. Boxall (1994; cited in Budhwar, 2001, p. 800) contends that all the workforce developments have taken place over the last two decades or so.As a result, the nature of HR function has changed from being reactive,prescriptive and administrative to being proactive, descriptive and executive.

Valuing HR is based practically on management perspective, defined as Human ResourcesManagement (HRM). HRM gained a more critical and strategic role (HejaseRifai, Tabsh, \&Hejase, 2012, p. 28). Today, in a world of increased 
competition, the role of the HR manager is more significant. It seems that the future will rely more on intellectual capital, i.e. how to retain and manage the knowledge of the workers.

There is a wide range of HRM approaches applicable to specific settings, but mostly fall within a workforce commitmentorganizational performance framework. Armstrong (2009, pp. 887-8) summarizes prescriptions that constitute an HRM model as follows:

- A drive for commitment - winning the 'hearts and minds' of employees.

- An emphasis on mutuality - getting the message across that 'we are all in thistogether'.

- Complementary forms of communication: teambriefings, traditional collective bargaining, approaching employeesdirectly.

- A shift from collective bargaining to individual contracts.

- The use of employee involvement techniques such as improvement groups.

- Continuous pressure on quality - total quality management.

- Flexibility in working arrangements: multi-skilling, secure employment for the 'core' workers, teamwork.

- Harmonization of terms and conditions for all employees.

Nowadays, HRM is evolving and is becoming more sophisticated.IBM developed a "High-impact learning organization ${ }^{\circledR}$ maturity model" that shows the status of workforce at different maturity stages. It covers four entities: HR administration, Enterprise administration,Integration with talent strategies, and Learningculture(Cheng, 2013).

The aforementioned developments respond to businesses changes."HR needs to be creative and new competencies are required;we are observing a number of developments in the corporate world that are having an impact on HR" (Eigenhuis\&Dijk, 2007), namely:

- Corporate governance;

- Teams;

- HR as contributor to the business;

- International HR competencies required;

- Productivity drive;

- The growing importance of private equity;and

- HR outsourcing (p. 165).

Since achieving higher organizational performance has been mainly the drive behind the changing workforce status, HRM practices have been widely researched. They aimed to tie the individual employee's work performance to organizational outcomes (Hoedemaekers, 2008, p. 11; Armstrong, 2009, p. 231). Combining HR status and high-performing demands resulted in a reconciliation that has been attempted through High-Performance Work Systems (HPWS); the aim of HPWS is "to achieve a high-performance culture, one in which the values, normsand HR practices of an organization combine to create a climate in which the achievement of high levels of performance is a way of life" (Armstrong, 2009, p. 231).

Additional findings continue to benefitthe HR. Monavvarian and Khamda (2010) state that the global competitive environment requires an element that holds much more value than technology, natural resources and even money; it is "knowledge". They cite Burk as stating "knowledge management is 80 percent people and 20 percent technology" (p. 21).

Businesses question the effects of lack of performing HR on their organization. According to Manpower Group (2013), an international periodical studyhave found that the shortage of talents has reduced employers' ability to adequately serve clients by $43 \%$, competitiveness by $39 \%$, and creativity and innovation by $22 \%$. All of these affected abilities are differentiated forms of targeted organizational performance (pp. 2, 10).

Referring to the aforementioned, one finds that in the Arab countries, researchers urge the development of HR to respond efficiently to enormous underway technological developments throughout the world (Al-Banna, 1999 and Al-Khawaja, 1999; cited in LCPS, 1999, p. 11 \& 14).

\subsection{Culture and Performance}

International and comparative HR development researches, regardless of specific topics studied, continually refer to culture as a matter of central importance when dealing with the factors affecting HR performance (Dirani, 2006, p. 87).

How is performance valued?What optimizes this human potential? How to achieve a high-performance culture? These questions are discussed next. In some cultures, it is normal to celebrate successes; while inothers, celebration of success does not happen naturally and needs to be organized (Eigenhuis\&Dijk, 2007, p. 69).Intrinsic appreciation of performance energizes and sustains potential further than external projected or adapted motivation rewards. Intrinsicalness in this sense is closely related to individual's values and beliefs for the long term, and to culture at a societal level. House et al. (2004) define culture as: 
"shared motives, values, beliefs, identities, and interpretations or meanings of significant events that result from common experiences of members of collectives that are transmitted across generation"(p. 15).

Bhawuk (2003, p. 2) argues that people strive to excel in areas thatare valued in a culture, andsupports the idea that culture plays acritical role in the shaping of creative behaviors as introduced byTriandis's (1994) and Simonton's (1996)works (Fig. 1).

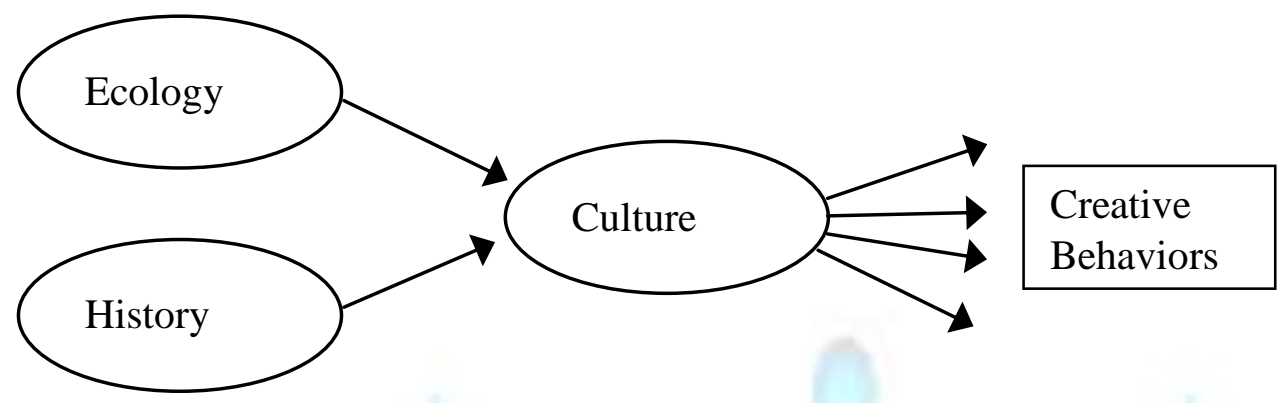

Figure 1. Culture as Antecedent of Creative Behaviors (Source: Bhawuk, 2003, p. 3)

Bhawuk (2003) contends that Simonton (1996, 1988; cited in Bhawuk, 2003), who also builds on Kroeber's (1944) works, concluded in a historiometric study that genius is shaped by thecultural configuration, and marshaled evidence that geniusesthat appear in a local configuration, or new innovations, are a result of the social situation (p. 4). Business performance strategists are promoting socializing business to optimize outcomes. Nurturing and promoting talents does not happen in an isolated environment, but within a society alongside its culture.

Simonton (2003, pp. 304-328), in his research on creative national cultures, argues that the coming and going of great creative genius in various times and places can be better attributed to changes in the cultural, social, political and economic circumstances. The aforementioned circumstances determine the extent to which the resulting milieu nurtures the development of creative potential and the expression of that developed potential.Goethe (1749-1832), a German philosopher, calls it "Zeitgeist". The Zeitgeist represents the political, cultural, economic, social, and disciplinary circumstances that affect the quantity and quality of creativity in a particular time and place (Runco\&Pritzker, 2011, pp. 533-538).These are nothing but culture, or culture patterns. Theyconstitute the capital of a nation. A nation's "human capital endowment," defined as individuals' capabilities put to productive use on behalf of society, can be a more important determinant of its long-term economic success than virtually any other resource (World Economic Forum, 2013b, p. 3). Human capital is even more valuable in an era of global competition, as workers across the world are increasingly available to companies looking for the top talent.

The effort to encouragethe HR to be more efficient and creative is defined as Human Resource Development (HRD). HRD may also expand and have a greater impact and framework. HRD is "any process or activity that, either initially or over the long term, has the potential to develop adults' work-based knowledge, expertise, productivity and satisfaction, whether for personal or group/team gain, or for the benefit of an organization, community, nation or, ultimately, the whole of humanity" (McLean \& McLean, 2000, p. 322). Yet, this expanded definition does not rule out or cancel characteristics of each nation. Hall (2005; cited in Mankin, 2009, pp. 15-26) indicates that the greatest challenge facing HRD practitioners working in an international capacity is how to operate effectively at both a global and a local level.Variations in HRD practices and systems are directly linked to the socio-cultural variations (Dirani, 2006, p. 86). While HRD and National Vocational Education and Training(NVET) may be used interchangeably, NVET focuses on developing a country's human capital and presents a strategic response to the long-term skills that its indigenous private, public, and non-profit sectors need(Mankin, 2009, pp. 15-26).

As for the Arab countries, Metcalfe and Rees (2005; cited in Mankin, 2009, pp. 15-26) foundthat little attention has been given to Middle East countries, although several countries, Bahrain, Kuwait, Jordan, Oman, and the United Emirates have national HRD programs.

\subsection{Dimensionalizing Culture}

Culture represents a human concept. Since culture is differentiated and immeasurable, related applications varied according to cultural configurations; even though, huge researches have been executed to extract scalable common dimensions of culture with an aim to interpret management styles or even community patterns. Today widely cited findings of Hoftstede's works have come outstrongly. Hofstede $(1983,2011)$ initiated in year 1967 a survey across sixtyseven countries, where his international employer (IBM), aimed to assess employees' satisfaction. Observing differences in such highly structured company provoked him to refer such behavior to the country's context. Sets of similar contextrelated behaviors were sorted out, initially four dimensions in 1972, then, in 2007, six were concluded:

1) Power Distance (PD), relates to solutions to the basic problem of human inequality.

2) Uncertainty Avoidance (UA), relates to stress in the face of an unknown future. 
3) Individualism vs.Collectivism, relatesto individuals'integration into groups.

4) Masculinity vs.Femininity, relates to gender inequality.

5) Long vs. Short Term Orientation, relates to focus on the future or the present / past.

6) Indulgence vs. Restraint, relates to gratification vs. control of basic human desires.

The aforementioned study has paved the way for additional researches and findings by Hofstede and others. House et al. (2004) initiated in 1991 a study on 'Global Leadership and Organizational Behavior Effectiveness (GLOBE)' to investigate cultural dimensions worldwide. They coordinated ateam of more than 170 researchers from 62 countries, for 13 years, to review the extensive literature on this topic; they surveyed 17,300 managers of different industries.GLOBE findings manifested nine cultural dimensions that stimulate behavior of society or organization's members:

1) Power Distance(PD):the degree to which membersexpect and agree that power should be stratified andconcentrated at higher levels of an organization orgovernment.

2) Uncertainty Avoidance (UA):the extent to which members strive to avoid uncertainty of future events by relying onestablished social norms, rituals, and practices.

3) Assertiveness:the degree to which members are assertive, confrontational, and aggressive in socialrelationships.

4) Institutional Collectivism: the degree to which institutional and societalpractices encourage and reward collective distribution ofresources and collective action.

5) In-Group Collectivism: the degree to which individuals express pride, loyalty, andcohesiveness in their organizations or families.

6) Future Orientation:the degree to which individuals engage in future-oriented behaviors such as planning,investing in the future, and delaying gratification.

7) Performance Orientation (PO):the degree to which an institution encouragesand rewards group members for performance improvement,innovation, and excellence.

8) Humane Orientation:the degree to which individuals are encouraged and rewarded for being fair, altruistic,friendly, generous, caring, and kind to others.

9) Gender Egalitarianism:the degree to which an institution minimizesgender role differences while promoting gender equality.

Based on the obtained results, societies were ranked. If to investigate how far a society is individualistic, humanistic or future-oriented, then individualswill be surveyed through questionnaire items validated for that construct. Researchers concluded patterns of each dimension, but many still warn against post hoc approach. Indicators of underdevelopment economics would not necessarily mean un-valuing of performance. This requires further research, which involves many factors of different domains.

\section{RESEARCH HYPOTHESES}

Few papers investigated cultural dimensions of Lebanese society. Within such relative scarcity, researches have clustered Lebanon either among Arab countries (Hofstede, 1983; 2001) or among Middle East countries (House et al, 2004), or rarely studied it independently. Therefore, a basis for thecurrent research's hypotheses is thereported literature, mostly on Arab countries. Many researchers (House et al, 2004; Hofstede, 2001; Kabasakal\&Bodur, 2002; Ronen \&Shenkar, 1985) assumedhomogeneity of values and practices among Arab or Middle East region. This research paper aims to highlight Lebanon's culture followingSidani\&Garder's (2000) approach to encourage the verification, and not the assumption of, any claimed common patterns (p. 605), rather than assessing the differences sincein addition to historical evidences, current economic and political conditions in this region would questionsome of the claimed similarities, even for countries identified as part of an Arab cluster (Ralston, 2012, p. 481).

Developing hypotheses on Lebanese cultural characteristics and testing them empirically helps to fill the aforementioned gap and advance understanding of Lebanese practices. At the same time, it highlights the necessity of avoiding generalizations (Elsaid\&Elsaid, 2012, p. 1) concluded by cultural studies in non-Arab countries.

Limiting this research to four cultural dimensions (Performance Orientation (PO), Future Orientation (FO), Collectivism (COL) and Power Distance (PD)) engrave contention of theirwide recognition (House et al, 2004; Hofstede, 2011), and vital impact on HR capacity and community development.

As to 'Performance Orientation' (PO) dimension, the Arab group scored high in masculinity (Hofstede, 1983; 2001), which is considered as an antecedent to PO (Robertson et al, 2002, p. 586). GLOBE (House et al, 2004) found four Arab countries (Egypt, Morocco, Kuwait and Qatar) record almost neutral (3.45-4.2 on a scale of 7) on PO scale, and clustered the aforementioned countries under Middle East. In a study on entrepreneurship in Lebanon,Chakour (2001, p. 41) concluded that Lebanese strongly encourage performance, considering successful entrepreneurs as champions and role models (Ahmad \& Julian, 2012, p. 28). Thus, the proposed hypothesis one is:

$\mathrm{H}_{1}$ : Lebanese societal culture correlates positively with 'Performance Orientation'. 
Almost similar to findings on performance scale, Arab countries scored on 'Future Orientation (FO)' scale below the median value (3.26-3.86) (House et al, 2004), which means they do not practice enough future planning. Hajazi(1979, cited in Sidani\& Gardner, 2000, p. 600), indicated that the current Arab value system leads to a lack of future programming or planning; and, Ali (1987; cited in Sidani\& Gardner, 2000, p. 600), concluded that this drawback leads to carelessness and frustration. Therefore, since there is no direct investigation of Lebanese future attitudes, the researcherspropose,backed byliterature on entrepreneurship and emigrationspirit (Ahmad \& Julian, 2012; Sayigh, 1962; Chakour, 2001) manifested by the people of Lebanon, hypothesis two:

$\mathrm{H}_{2}$ : Lebanese societal culture correlates positively with 'Future Orientation'.

The Arab group in Hofstede's (1983; 2001) study scored high in Collectivism (COL), while little above average in GLOBE study (House et al, 2004).Buda and Elsayed-Elkhouly (1998; cited in Ralston et al., 2012, p. 483) found the Middle East samples to be collectivistic, and that Egyptians were more individualistic than their Gulf counterparts.

Some COL patterns do not prevail in Lebanon as it is in other Arab countries (Ahmad \& Julian, 2012; Chakour, 2001).Therefore, and as no clear-cut orientation, the third hypothesis will be:

$\mathrm{H}_{3}$ : Lebanese societal culture correlates positively with 'Collectivism'

All literature reviewed (Hofstede 1983; 2001; House et al., 2004; Dirani, 2006; Robertson et al., 2002) suggested high Power Distance(PD) for Arab countries and generalized for Lebanon. Thus, it will be proposed that

$\mathrm{H}_{4}$ : Lebanese societal culture correlates positively with 'Power Distance'

\subsection{Lebanon}

Researchers (Sidani\& Gardner, 2000; Dedoussis, 2004; Nauffal, 2004; Dirani, 2006; Lahoud, 2008; Charbaji, 2009; Tleis\&Kauser, 2010; Ahmad \& Julian, 2012) emphasized cultural context as a vital influencing factor on different topics investigated and analyzed in Lebanon. Therefore, the researchers in this paper present a brief discussion about the Lebanese society, including few historical facts.

\subsubsection{Brief History}

Lebanon is locatedin Asia, at eastern Mediterranean coast, in the western Arab region. Although Lebanon is a small country (Area: $10452 \mathrm{~km}^{2}$, Population: 4.2 million resident), it has been featured with rich history, religious diversity, westeast geographical knot. Roman, Byzantine, Crusader, Mameluke, Ottoman and French occupants have resided in Lebanon for different periods and affected its societal and political culture (Lahoud, 2008, p. 391).In 1943, Lebanon was declared independent, but French colonialism left behind well-established educational, economic and political western francophone institutions (Dirani, 2006, p. 89).Today, the Lebanese are 59.7\% Muslims and 39\% Christians (CIA World Factbook, 2013) of different sects. There is a Jewish minority, but has mostly immigrated.

Lebanese pride themselves on being the grandsons of Phoenicians, who invented the alphabet (Dirani, 2006, p. 89), and were forerunner of ships'manufacturing and as over-sea traders. Though Lebanon was labelled the Switzerland of the East (ibid, p. 89), the Lebanese kept their eyes on the far seas for better business opportunities; for example,the Americas, Australia and New Zealand, Africa and the Arab oil countries.Emigration has forged strong ties with the outside world and been of great influence on the transmission of ideas, new methods, and new forms of organization, as well as remittances (Ahmad \& Julian, 2012, p. 25).Lebanese expatriates also helped neighboring Arab countries assume the role Lebanon played before the civil war (1975-1990) (Dirani, 2006, p. 90).

TheLebanese civil war between 1975 and 1990 turned new hopes of economic wealth down. Dirani (2006, p. 89) concludes that the period since the war stopped in 1990 has presented one of thebiggest challenges that Lebanon has faced in its briefhistorical existence. Lebanon is suffering a deep-rootedwar mentality and consequences.By the end of the fiscal year 2012, Lebanon had been struggling to cope with a gross public debt that amounted to USD 57.7 billion (Ministry of Finance, 2013, p. 46).In 2004 and 2007 (after 2006 war), about 50\% of young people (15-25 years) emigrated either for job-seeking or change of residency; 44\% of Lebanese expatriates between 2004 and 2009 were graduate people (CAS, 2013a, p. 9). In a recent study on Lebanon, Gaillard (2010, p. 92; 2007a) estimated that at least half the Lebanese scientists lived outside the country. The labor force in Lebanon, in general, is considered overeducated for the needs of the local market. This reality, combined with the economic recession, hasled an estimated 5,000 to 10,000 young people each month to emigrate (Dirani, 2006, p. 90), and resulted in surprising moderate unemployment rate of $6.4 \%$ for the year 2009 (CAS, 2013b, p. 19).

Lebanon has a unique proportional representative political system based on confessional groups that stems directly from its diversity and its history of sectarian division. Lebanon suffered several Israeli invasions, whose occupation lasted until 2000.

\subsubsection{The Culture of Lebanon}

Hofstede (1997, p. 54; 2001, p. 52) emphasized differences among Arab countries like Saudi Arabia, Egypt and Lebanon. The Lebanese society exhibits culture receptiveness and flexibility with respect to accommodating values from other cultures (Dedoussis, 2004, p. 30).Hakim (1966; cited in Dirani, 2006, p. 92) argued that the Lebanese society is more of an open way of life that allows the free entry andexchange of cultural and intellectual influences, whether Arab or Western, capitalist or communist. This unique pluralistic and differentiated social structure had a major effect on shaping the nontraditional and westernized characteristics of Lebanese individuals. 
According to Khalaf(1987) and Super (1988),(both cited in Dirani, 2006, p. 91)the family is the most important social structure in Lebanon, and has a major effect on the development of vocational preference and on individual achievement motivation. In addition,Jabbra(1989; cited in Dirani, 2006, p. 92) found that Lebanese society places aspecial emphasis on social conformity rather than on creativity or innovation; a fact confirmed earlier by Hofstede's (1984) who asserted the largePD and UAas predominant dimension characteristicsfor Arab countries, which means obedience to authority and control.Moreover, Lebanese workers are less likely to be driven by an internalized need for achievement than are their western counterparts.Lebanon, as well as other Arab countries, continuously experiences the duality between the East and the West, the religious and the secular. These dualities create conflicting expectations of the leaders in this society regarding relationships and performance. Lebanese professionals have the knowledge, experience and skills; they just need the will and vision to make the change.

Though Lebanon accommodates strong religious and cultural norms as well as modern values (Tleis and Kauser, $2010, \mathrm{p}$. 465), and has been described as the pioneer in the Arab region for enjoying relaxed codes regarding women's participation in different activities (Sidani, 2005), gender equality has remained below desired levels (Tlaiss\&Kauser, 2010, p. 464). Hejase et al (2014) concluded that women earn less than their male counterparts do, and that the discrimination increases as both women and men move towards the top positions (p. 442).

\subsubsection{Current Indicators}

\section{Education}

Lebanon is more advanced and prestigious in the education sector,comparable to neighboring countries. Literacy statistics in Lebanon indicate $98.7 \%$ for ages $15-24$, and $89.6 \%$ for adults (CAS, 2013a). This result is in accordance with unjustified high expenditures on education comparable to developed countries: Lebanon records $11.4 \%$ of GDP, while Japan, France and USA record $4.8 \%, 6.2 \%$ and $7.1 \%$ respectively.More surprising is the high portion families contribute to education: $7 \%$ in Lebanon, $0.4 \%$ in France, $1.2 \%$ in Japan and 2.2\% in USA (CRD, 2014). The researchersin this paper believe that the aforementioned education to GDP ratio could be much higher. Such high expenditure demand pressures on Lebanese workforce to afford it. This high investment in education does not result in higher research and innovation in technology except if supported by the government or funded programs from private initiatives. Recently, BouJaoude and Abd-ElKhalick (2004) conducted asurvey among ten Lebanese universities, which offer different education programs including health sciences, engineering, arts and sciences, and business. Theyfound that these programs, combined, conducted sixty-two empirical scienceeducation studies in Lebanon between the years 1992 and 2002. The researchersnoticed that only eighteen manuscripts were published in refereedjournals, in a period of ten years.

\section{Economy, Globalization and Technology}

The banking industry in Lebanon is considered one of theimportant sources of the country's gross domestic product (6.2\% of GDP), and a significant income-generator (Association of Banks in Lebanon, 2013, p. 10). Lebanon's openness totechnology and globalization is unique in the Arab World. Lebanon has the potential tobecome a major player in international networking by playing the role of intermediary between the global economy and the region. It can assess the currentstate of Information Technology (IT) and assist in the transfer of technology to the region because of its relativetechnological advancement and the superior skills of its labor force. The aforementioned characteristics could alsoprovide work opportunities for new graduates (Dirani, 2006, pp. 93-94). Report on Human Capital Index (WEF, 2013b),Table 1, shows Lebanon's ranks in different sectors: best in education and worst in enabling enviroment in Middle East and North Africa (MENA) region.

\begin{tabular}{l} 
Table 1.Lebanon's Human Capital Index 2013 \\
\multicolumn{1}{|l|}{ Rank/122 } \\
\hline \begin{tabular}{|l|c|}
\hline Human Capital Index 2013 & 74 \\
\hline Pillar 1: Education & 32 \\
\hline Pillar 2: Health and Wellness & 77 \\
\hline Pillar 3: Workforce and Employment & 96 \\
\hline Pillar 4: Enabling Environment & 104 \\
\hline GDP per Capita PPP (\$) & 12,592 \\
\hline
\end{tabular}
\end{tabular}

Source: WEF, 2013b.

Not shown in Table 1, but worth mentionting, are more different ranks depicted by the workforce and employment pillar, where 'country capacity to attract and retain talent' (Rank: 97 and 99/122), and the education pillar where 'ease of finding skilled employees' (30/122), and 'capacity for innovation' (78/122) are salient. 
Moreover, the Lebanese HR potential is also categorized in other different global reports. In the Global Competitiveness Report 2012-2013 (WEF, 2013a), Lebanon ranks 91 out of 144. Its economy lies in the transition stage from efficiency drive towards innovation drive.In Human Development Report 2013 (UNDP, 2013), Lebanon ranks 72 out of 187 countries. Although the ranks are not very high, they reflect future potential if the right planning exists.

\section{Corruption}

Corruption weakens the administration, increases the costs of development programs, undermines revenue-collection capacities, creates economic and financial difficulties, and distorts the formulation and implementation of public policy (EI Jurdi, 2010, pp. 23-24). Moreover, the corrupt war mentality that is evident in the incompetent employees with diminutive productive capacity and the motivational values underlying performance of workers especially in the public sector, as well as the general climate in the Middle East, remain obstacles to the attempts at business reform (Harnish, 2003; cited in Dirani, 2006, p. 91), and the eradication of corruption. Furthermore, the National Integrity System report on Lebanon (Lebanese Transparency Association, 2011) states that Lebanon ranked 102 out of 180 countries $\left(11^{\text {th }}\right.$ out of 20 countries ranked inthe Arab region) on the 2008 Corruption Perceptions Index (CPI); a poor score based onthe weaknesses of the institutions reviewed. On the 2008 Open Budget Index(OBI) that measures transparency in the national budget process, Lebanonscored 32/100. Finally, on the World Bank's Worldwide Governance Indicators (2009, July), Lebanon received scores that clearly highlightincreased corruption in the country. Lebanon is ranked $146^{\text {th }}$ out of 212 countriesin terms of government efficacy, 202 in terms of political stability, $108^{\text {th }}$ in termsof voice and accountability, and $167^{\text {th }}$ in terms of corruption control, which isbelieved to be "the report's most perturbing data" (p. 26).

Although intheory, much of the framework for a Lebanese integrity system that provides themechanisms to support a democratic government appears to exist (especiallyas compared to Arab counterparts in the region); in practice, each of the reviewed integritypillars faces significant challenges that threaten good governance.In stating obstacles to doing business, infrastructure, bureaucracy, political instability and corruption appear to be the most impeding.

\section{METHODOLOGY}

This studyuses a quantitative descriptive approach to exploreLebanese cultural dimensions affecting levels of universities' HR performance in Lebanon. The selected HR personnelare represented by university staff and instructors from a number of Lebanese universities. Data is analyzed with support of Statistical Product and Service Solutions (SPSS), an IBM product acquired by IBM in 2009 (Hejase\&Hejase, 2013, p. 58). Verified patterns of each cultural dimension should approve its scale level.

\subsection{Questionnaire Design}

For surveying purposes, a closed-end Arabic questionnaire was designed by the researchers. Five-level Likert scale statements are used, including demographic and culture-specific items. The questionnaire is composed of four construct scales, each havingthree to five items. Each construct relates to a cultural dimension concluded by GLOBE and Hofstede researches:PO, FO, COL andPD. The focus of the items is on patterns of each cultural dimension to provide evidence of support practiced. It is worth mentioning that the questionnaire items are constructed based on extensive literature review of culture-related behaviors and international validated scales; for example, Table 2 shows literature review findings on patterns of PD dimension. The GLOBE study introduced a comprehensive literature review as part of its methodology to support a global common understanding of cultural dimensions. Therefore, to avoid duplication, citations to these correlations are at large from GLOBE study, with reference to its original source where applicable.

Table 2.Research Findings related to 'Power Distance'

1- GLOBE (House et al., 2004)

High PD preempts the society from questioning / learning as there is little opportunity for debate and divergent views. Questioning may be interpreted as blaming, and therefore may be prohibited.

Within the low PD cultures, the flexible distribution of power facilitates entrepreneurial innovation, allows broader participation in education, and helps constrain the abuse of power and corruption.

The enhanced use of technology is likely to reduce the arbitrary use of authority.

$\mathrm{PD}$ is associated with higher levels of male domination in societies.

PD index tended to be higher in lower-skilled occupations than among professional workers such as engineers and scientists (Hofstede, 1980; 1994).

In societies that practice $\mathrm{PD}$, there is less emphasis on integrating different societal groups (Chinese Culture Connection, 1987).

PD reduction in the organizations adds to the employees' beliefs of self-efficacy and self-control, adds to their work satisfaction, and enhances growth and productivity (Huselid, 1995; Nadler, 1989).

$\mathrm{PD}$ is one of the important constructs that can distinguish whether a society is collectively or individually oriented (Smith, Dugan, and Trompenaars, 1996). 
In high PD countries, the respect a person gets is highly dependent on his/her family background (Trompenaars and Hampden-Turner, 1998).

Cooperative and voluntary negotiation characterizes low PD and egalitarianism (Schwartz, 1999).

\section{2- Dedoussis, 2004}

Local Jordan companies suffer from an excessive lack of delegation of authority. Participative leadership style is not appreciated by Jordanian managers (Al-Faleh, 1987; Al-Rasheed, 2001).

Respect for seniority and authority, as determined by age, family, and sex, is a feature of many Arab countries (Barakat, 1993; Ali and Wahabi, 1995).

In Arab countries,preference is for hierarchical communication and tall organizations with systems and structures that bind the individual to the group.

Note: References inside the document are cited in the main two references presented as titles.

Previous researchers concluded that societies with a lower degree on PD tend to be decision sharing and cooperative (Schwartz, 1999; cited in House et al, 2004). Another characteristic of PD higher degree is hierarchical and patriarchal (House et al, 2004, p. 523), from which the current researchers have concluded items like how to attain higher job positions. Therefore, a set of 8-10 itemsare proposed based on the literature review but modified to accommodate the Lebanese context.These items were analyzed for reliability and correlations to ensure their validity. The authors intentionally reversed the write-up of few questions to 'minimize the danger of acquiescent response bias, i.e. the tendency for respondents to agree with a statement, or respond in the same way to items' (Rattray\& Jones, 2007, p. 237).

\subsection{Sampling}

This study explores human concepts at diversified societal levels. Therefore, stratified sampling is used. HR at Lebanese universities constitutes the sample society, for they have a wide influence on future HR, and are expected to express their views well. Each university is a stratum selected with specific standards to meet societal and geographic variability. Four universities represented urban and rural communities of different incomes. The total sample size of 204 is considered adequate based on $95 \%$ confidence interval ( $p<0.05$ ), with margin for random error of $\pm 10 \%$ and computation of pilot's standard deviation (Hubbard \& Lin, 2011, p. 16; Fox, Hunn, \&Mathers, 2009, p. 19). Calculations suggested 51 cases to be surveyed. Table 3 shows universities' characteristics and volunteer participants' size; participants were promised anonymity.

Table 3.Descriptive Statistics and Sample Sizes of Each University

\begin{tabular}{|c|c|c|c|c|c|}
\hline & LAU & IUL & UA & AUST & Total \\
\hline Est. Year & 1924 & 1996 & 1996 & 2000 & \\
\hline Faculty \& Staff & 823 & 587 & 428 & 525 & \\
\hline Students & 6320 & 4811 & 2445 & 5015 & \\
\hline Tuition Fees & Very High & Middle to Low & Middle & Middle to High & \\
\hline Location & Beirut & Aalieh & Baabda & Beirut & \\
\hline Sample size & 72 & 53 & 51 & 34 & 210 \\
\hline
\end{tabular}

\subsection{Quantitative Analysis}

The authors generated an initial draft of 62 items divided into: PO: 22, FO: 15, COL: 14, and PD: 11;thus, reflecting the scope of the constructs. Then, when compared to findings of correlations between cultural factors and HR performance, items were filtered to 31 (PO: 7, FO: 7, COL: 8, PD: 9), [which were then examined and approved by three independent professors].A pilot study on about $10 \%$ of sample size helped to test its acceptability and reliability as detailed below.A similar approach to design a questionnaire was followed by Sharma (2010) and Bik (2010).

\subsubsection{Validity and Reliability}

Items should show high levels of statistical validity and reliability (Lee, 2006, p. 761). Reliability analysis tests internal consistency, or how far the scale items measure the same construct (Nauffal, 2004, p. 77). A Cronbach coefficient ( $\alpha$ ) equals about 0.7 or greater (Yordanova, 2011, p. 25, Hejase\&Hejase, 2013, p. 570) meets the reliability condition.

Tables 4, 5 and 6 display reliability values derived for drafted and final PD items. Table 5suggests removing items 3 and 4 to enhance Cronbach's Alpha value to (0.943). 
Table 4.Reliability Analysis of Drafted Nine PD Items

\begin{tabular}{|c|c|}
\hline Cronbach's Alpha & N of Items \\
\hline .928 & 9 \\
\hline
\end{tabular}

Table 5.Item-Total Statistics

\begin{tabular}{|c|c|c|c|c|}
\hline & $\begin{array}{c}\text { Scale Mean if } \\
\text { Item Deleted }\end{array}$ & $\begin{array}{c}\text { Scale Variance } \\
\text { if Item Deleted }\end{array}$ & $\begin{array}{c}\text { Corrected Item- } \\
\text { Total Correlation }\end{array}$ & $\begin{array}{c}\text { Cronbach's Alpha if } \\
\text { Item Deleted }\end{array}$ \\
\hline $\mathbf{1}$ & 20.8000 & 55.700 & .869 & .911 \\
\hline $\mathbf{2}$ & 21.0000 & 60.500 & .813 & .914 \\
\hline $\mathbf{3}$ & 20.6000 & 64.300 & .607 & .928 \\
\hline $\mathbf{4}$ & 21.6000 & 77.800 & .089 & .943 \\
\hline $\mathbf{5}$ & 21.8000 & 52.200 & .939 & .906 \\
\hline $\mathbf{6}$ & 21.0000 & 61.500 & .758 & .918 \\
\hline $\mathbf{7}$ & 21.2000 & 64.200 & .956 & .911 \\
\hline $\mathbf{8}$ & 21.8000 & 67.700 & .902 & .915 \\
\hline $\mathbf{9}$ & 20.6000 & 60.800 & .797 & \\
\hline
\end{tabular}

Without PD items 3 and 4, reliability analysis scored (0.951), as shown in Table 6.

Table 6. Reliability Statistics without items 3 and 4

\begin{tabular}{|c|c|}
\hline Cronbach's Alpha & N of Items \\
\hline .951 & 7 \\
\hline
\end{tabular}

Table 7 displays Alpha values if any item is removed. All values suggested are below the induced one (0.951). Therefore and to reduce each scale's item to five, the authors checked in a final step for minimal Inter-Item Correlation values (Table 8). Analysis of items inter-correlations strengthens its consistency, where a minimal value of 0.6 is considered satisfactory in exploratory research(Hair, Anderson, Tatham, \&Black, 1998). Since neither reliability analysis, nor Inter-Item Correlation Matrix show inconsistent values, the authors chose to take out any two items; here, 7 and 8.

Table 7. Item-Total Statistics without items 3 and 4

\begin{tabular}{|c|c|c|c|c|}
\hline & $\begin{array}{c}\text { Scale Mean if } \\
\text { Item Deleted }\end{array}$ & $\begin{array}{c}\text { Scale } \\
\text { Variance if } \\
\text { Item Deleted }\end{array}$ & $\begin{array}{c}\text { Corrected Item- } \\
\text { Total Correlation }\end{array}$ & $\begin{array}{c}\text { Cronbach's } \\
\text { Alpha if Item } \\
\text { Deleted }\end{array}$ \\
\hline $\mathbf{1}$ & 15.4000 & 44.800 & .803 & .948 \\
\hline $\mathbf{2}$ & 15.6000 & 46.800 & .886 & .938 \\
\hline $\mathbf{5}$ & 16.4000 & 40.300 & .955 & .935 \\
\hline $\mathbf{6}$ & 15.6000 & 47.300 & .853 & .941 \\
\hline $\mathbf{7}$ & 15.8000 & 51.700 & .917 & .942 \\
\hline $\mathbf{8}$ & 16.4000 & 54.300 & .912 & .948 \\
\hline $\mathbf{9}$ & 15.2000 & 48.200 & .795 & .946 \\
\hline
\end{tabular}


Table 8.Inter-Item Correlation Matrix without items 3 and 4

\begin{tabular}{|c|c|c|c|c|c|c|c|}
\hline & $\mathbf{1}$ & $\mathbf{2}$ & $\mathbf{5}$ & $\mathbf{6}$ & $\mathbf{7}$ & $\mathbf{8}$ & $\mathbf{9}$ \\
\hline $\mathbf{1}$ & 1.000 & .606 & .822 & .728 & .884 & .894 & .606 \\
\hline $\mathbf{2}$ & .606 & 1.000 & .886 & .853 & .772 & .813 & .912 \\
\hline $\mathbf{5}$ & .822 & .886 & 1.000 & .886 & .968 & .816 & .775 \\
\hline $\mathbf{6}$ & .728 & .853 & .886 & 1.000 & .772 & .813 & .618 \\
\hline $\mathbf{7}$ & .884 & .772 & .968 & .772 & 1.000 & .791 & .729 \\
\hline $\mathbf{8}$ & .894 & .813 & .816 & .813 & .791 & 1.000 & .813 \\
\hline $\mathbf{9}$ & .606 & .912 & .775 & .618 & .729 & .813 & 1.000 \\
\hline
\end{tabular}

Tables 9 and 10 display the reliability analysis and inter-item correlation values of final PD items. Cronbach's Alpha scored (0.94), whilecorrelationvalues ranged between 0.61 and 0.91 , and lie far above the minimal requirement $(0.4)$.

Table 9. Reliability Statistics of final PD items

\begin{tabular}{|c|c|}
\hline Cronbach's Alpha & N of Items \\
\hline .940 & 5 \\
\hline
\end{tabular}

Table 10.Inter-Item Correlation Matrix of final PD items

\begin{tabular}{|c|c|c|c|c|c|}
\hline & $\mathbf{1}$ & $\mathbf{2}$ & $\mathbf{5}$ & $\mathbf{6}$ & $\mathbf{9}$ \\
\hline $\mathbf{1}$ & 1.000 & .606 & .822 & .728 & .606 \\
\hline $\mathbf{2}$ & .606 & 1.000 & .886 & .853 & .912 \\
\hline $\mathbf{5}$ & .822 & .886 & 1.000 & .886 & .775 \\
\hline $\mathbf{6}$ & .728 & .853 & .886 & 1.000 & .618 \\
\hline $\mathbf{9}$ & .606 & .912 & .775 & .618 & 1.000 \\
\hline
\end{tabular}

Table 11 displays reliability values of considered cultural subscales PD, FO, PO and COL.

Table 11. Reliability Statistics of Final Subscales

\begin{tabular}{|c|c|c|c|c|}
\hline & PD & FO & PO & COL \\
\hline $\boldsymbol{\alpha}$ & 0.940 & 0.946 & 0.873 & 0.737 \\
\hline
\end{tabular}

As to validity, it means 'measuring what you think you're measuring' (Field, 2009, p. 332). For the reduced items, validity index is verified as follows:

Firstly,through corrected item-total correlation analysis, which should be greater than 0.2 so as to indicate a satisfactory degree (Pei et al., 2010, p. 1988). Table 12 shows how corrected item-total correlation coefficients of PD scale record far above minimal values $(0.75-0.95)$. 
Table 12. Corrected Item-Total Correlation of PD scale

\begin{tabular}{|c|c|c|c|c|}
\hline $\mathbf{1}$ & $\mathbf{2}$ & $\mathbf{5}$ & $\mathbf{6}$ & $\mathbf{9}$ \\
\hline .751 & .898 & .949 & .855 & .787 \\
\hline
\end{tabular}

\subsubsection{Factor Analysis}

Factor analysis procedure intends to reduce complexity of dataset and ensures factor groupings as proposed based onsatisfactory item-factor loading.An exploratory factor analysis (EFA) via Principal Component Analysis (PCA) with Varimaxrotation method applied on data collected serves this purpose.

What justifies which factor analysis' rotation method to run? 'Varimax' for unidimensional or 'Oblimin' for correlated factors? Unidimensionalityas to many cultural constructs is disputed (House et al, 2004, p. 463). In a review of scale development and validity,Bearden et al. (2006a), Soares et al. (2007), and Taras et al. (2009), all cited in Sharma (2010, p. 787),contend that most of these scales operationalize each cultural factor as a unidimensional construct, despite growing evidence to the contrary; they provide little or no evidence of their validity and cross-cultural measurement equivalence.Previous findings related one behavior to more than one cultural factor.In this study, a reliability analysis of all questionnaire items (four subscales) inferred a valueof (0.881) (Table 13). Thus, though items considered represented different latent constructs, it showed sometimes significant correlations and loadings with other factors. The authors of the current paperdo not aim to verify the unidimensionality, but have rather set a clearer grouping of the considered concepts.Varimax rotation method helps to differentiate interdependent constructs more than Oblimin rotation method. Table 15 shows how obliquity factor analysis infer vague or more inter-related grouping where it is not needed. Exploratory Factor Analysis (EFA) has led sometimes to the elimination of one or two of the proposed items of each subscale.

Table 13. Reliability Statistics of Total Questionnaire Items

\begin{tabular}{|c|c|}
\hline Cronbach's Alpha & N of Items \\
\hline .881 & 19 \\
\hline
\end{tabular}

Factor analysis was tested dually to ensure a clearer grouping: PD vs. COL andFO vs. PO. Tables14and 15 show how the final five proposed items loaded on each factor. Results suggest adequacy of FO5 for both subscales (PD vs. COL and FO vs. PO). The two factors have eigenvalues of 2.92 and 1.92 , and account for $48.4 \%$ of the total variance. All items loaded well above required value (0.4), except FO4 that will be omitted.

Table 14.Rotated Component Matrix of FO vs. PO

\begin{tabular}{|c|c|c|}
\hline \multirow{2}{*}{} & \multicolumn{2}{|c|}{ Component } \\
\cline { 2 - 3 } & $\mathbf{1}$ & $\mathbf{2}$ \\
\hline FO1 & & .722 \\
\hline FO2 & & .775 \\
\hline FO3 & & .624 \\
\hline FO4 & & \\
\hline FO5 & .461 & .437 \\
\hline PO1 & .633 & \\
\hline PO2 & .775 & \\
\hline PO3 & .709 & \\
\hline PO4 & .683 & \\
\hline PO5 & .626 & \\
\hline
\end{tabular}

Extraction Method: Principal Component Analysis.

Rotation Method: Varimax with Kaiser Normalization.

The same with other dimensions. One or two items may have been eliminated from their respective scale, where their loading valued below (0.4). 
Table 15. Structure Matrix of FO vs. PO

\begin{tabular}{|c|c|c|}
\hline & \multicolumn{2}{|c|}{ Component } \\
\hline & 1 & .722 \\
\hline FO1 & .470 & .774 \\
\hline FO2 & .517 & .624 \\
\hline FO3 & .555 & .436 \\
\hline FO4 & .605 & \\
\hline FO5 & .770 & \\
\hline PO1 & .735 & \\
\hline PO2 & .677 & \\
\hline PO3 & & \\
\hline \multicolumn{2}{|c|}{ PO4 } & \\
\hline Extraction Method: Principal Component Analysis. \\
Rotation Method: Oblimin with Kaiser Normalization \\
\hline
\end{tabular}

\section{RESULTS AND DISCUSSION}

Responses counted 210 instead of 204 ,six cases more than required, but not equally within the tested universities. Standard deviations (SDs) of all items ranged within (0.71-1.26), indicating adequate variance across participants.Demographic statistics are presented in Table 16.

Table 16. Demographic statistics

\begin{tabular}{|c|c|c|c|c|c|c|c|c|c|c|c|}
\hline \multirow{2}{*}{ Sample Size } & & \multicolumn{2}{|r|}{ LAU } & \multicolumn{2}{|c|}{ IUL } & \multicolumn{2}{|r|}{ UA } & \multicolumn{2}{|c|}{ AUST } & \multicolumn{2}{|c|}{ Total } \\
\hline & & 72 & $34.3 \%$ & 53 & $25.2 \%$ & 51 & $24.3 \%$ & 34 & $16.2 \%$ & 210 & $100 \%$ \\
\hline \multirow[t]{2}{*}{ Gender } & Male & 40 & $55.6 \%$ & 36 & $67.9 \%$ & 24 & $47.1 \%$ & 19 & $55.9 \%$ & 119 & $56.7 \%$ \\
\hline & Female & 32 & $44.4 \%$ & 17 & $32.1 \%$ & 27 & $52.9 \%$ & 15 & $44.1 \%$ & 91 & $43.3 \%$ \\
\hline \multirow[t]{5}{*}{ Job Position } & Dean & 2 & $2.8 \%$ & 3 & $5.7 \%$ & 2 & $3.9 \%$ & 1 & $2.9 \%$ & 8 & $3.8 \%$ \\
\hline & Chairman & 5 & $6.9 \%$ & 6 & $11.3 \%$ & 5 & $9.8 \%$ & 1 & $2.9 \%$ & 17 & $8.1 \%$ \\
\hline & Dept. manager & 10 & $13.9 \%$ & 12 & $22.6 \%$ & 6 & $11.8 \%$ & 4 & $11.8 \%$ & 32 & $15.2 \%$ \\
\hline & Instructor & 18 & $25.0 \%$ & 23 & $43.4 \%$ & 20 & $39.2 \%$ & 12 & $35.3 \%$ & 73 & $34.8 \%$ \\
\hline & Admin. Employee & 37 & $51.4 \%$ & 9 & $17.0 \%$ & 18 & $35.3 \%$ & 16 & $47.1 \%$ & 80 & $38.1 \%$ \\
\hline \multirow[t]{3}{*}{ Acad. Degree } & PhD. & 17 & $23.6 \%$ & 28 & $52.8 \%$ & 17 & $33.3 \%$ & 6 & $17.6 \%$ & 68 & $32.4 \%$ \\
\hline & Master & 34 & $47.2 \%$ & 15 & $28.3 \%$ & 21 & $41.2 \%$ & 19 & $55.9 \%$ & 89 & $42.4 \%$ \\
\hline & Bachelor & 21 & $29.2 \%$ & 10 & $18.9 \%$ & 13 & $25.5 \%$ & 9 & $26.5 \%$ & 53 & $25.2 \%$ \\
\hline \multirow[t]{3}{*}{ Years at Job } & $>10$ yrs & 40 & $55.6 \%$ & 21 & $39.6 \%$ & 20 & $39.2 \%$ & 16 & $47.1 \%$ & 97 & $46.2 \%$ \\
\hline & $5-10$ yrs & 14 & $19.4 \%$ & 25 & $47.2 \%$ & 21 & $41.2 \%$ & 11 & $32.4 \%$ & 71 & $33.8 \%$ \\
\hline & $<5$ yrs & 18 & $25.0 \%$ & 7 & $13.2 \%$ & 10 & $19.6 \%$ & 7 & $20.6 \%$ & 42 & $20.0 \%$ \\
\hline \multirow[t]{3}{*}{ Age } & $>40$ yrs & 33 & $45.8 \%$ & 17 & $32.1 \%$ & 18 & $35.3 \%$ & 12 & $35.3 \%$ & 80 & $38.1 \%$ \\
\hline & $30-40$ yrs & 24 & $33.3 \%$ & 31 & $58.5 \%$ & 20 & $39.2 \%$ & 11 & $32.4 \%$ & 86 & $41.0 \%$ \\
\hline & $<30$ yrs & 15 & $20.8 \%$ & 5 & $9.4 \%$ & 13 & $25.5 \%$ & 11 & $32.4 \%$ & 44 & $21.0 \%$ \\
\hline
\end{tabular}


$56.7 \%$ of the respondents are males and $44.4 \%$ are females. Instructors and administrative employees represented the majority with $34.8 \%$ and $38.1 \%$ respectively, while deans constituted $3.8 \%$ and chairmen $8.1 \%$. Participants with a PhD rated $34.4 \%$, and withMastersDegrees $42.4 \%$. Age and work-period averages are 30-40 and 5-10 years respectively.

\subsection{Hypotheses Testing Results and Implications}

Responses were analyzed with support of SPSS. Computations provided means and standard deviations for each surveyed cultural dimension, as presented in Table 17. Since questionnaire items target HR practices, scores represent 'As Is' cultural attitudes. The means of the responses corresponding to the three constructs PO, FO, and COL show significant values $(p>0.05)$ when compared to their claimed values $(\mu=3)$. While the PD construct ended up to be nonsignificant $(p \approx 0)$.

Table 17.Respondents' Means and SDs for each Dimension

\begin{tabular}{|c|c|c|c|}
\hline & Mean & Mean's SD & P-value $^{*}$ \\
\hline PO & 3.84 & .70 & $\mathrm{p} \approx 1$ \\
\hline FO & 4.10 & .57 & $\mathrm{p} \approx 1$ \\
\hline COL & 3.70 & .69 & $\mathrm{p}>0$ \\
\hline PD & 2.39 & .74 & $\mathrm{p}=0$ \\
\hline
\end{tabular}

* Assuming Null Hypothesis $\mathrm{H} 1_{0}: \mu \geq 3$ \& Alternative Hypothesis $\mathrm{H}_{1}: \mu<3$.

\section{$\mathrm{H}_{1}$ : Lebanese societal culture correlates positively with 'performance orientation'}

Table 17 showsthat the overall score mean of PO supports Hypothesis $1(p \approx 1)$. This result is consistent with prevailed societal spirit and previous research findings. Performance appraisal in Lebanese society expresses itself in a pride of history and many individual celebrities in and out of Lebanon. Chakour (2001) shows that Lebanese culture strongly supports self-enterprise as a sign of performance and considers successful entrepreneurs as champions and role models (Ahmad \& Julian, 2012, p. 28).

$\mathrm{H}_{2}$ : Lebanese societal culture correlates positively with 'future orientation'

Lebanon has suffered instability since the country's independence in 1943. However, do people tend to be future oriented? Respondents support positive correlation with FO $(p \approx 1)$, as displayed in Table 17; therefore, Hypothesis 2 is accepted. Firstly, the high need for this dimension also justifies its high score. People tend to emphasize what they feel they lack. Peng and Nisbett (1999; cited in House et al., 2004, p. 466) refer to this phenomenon as "deprivation-based preferences" at the individual level, wherein individuals express preferences for things that they believe they are lacking or things they have taken for granted.

Secondly, the Lebanese try to interpret FO with resources at hand, mostly individual- or in-group-based, due to lack of governmental institutional long-term planning. Wolf (1966, cited in House et al, 2004, p. 566) concluded that lack of formal welfare institutions, where resources are very unevenly distributed and where political power is often unstable, lead to the emergence of a system of patronage based on relationships of family and friends to fulfill some needs of individuals. Lebanese invest in education at the private level (7.0\%) higher than United States of America (2.2\%), Japan (1.2\%) and France $(0.4 \%)(C R D, 2014)$

$\mathrm{H}_{3}$ : Lebanese societal culture correlates positively with 'collectivism'

COL is a prevailed attitude in 'Eastern' cultures. Since Lebanon is an Arabcountry, it is expected to score high on this item. Table 17 shows a slightly over average COL mean of (3.70). Though respondents support Hypothesis 3 ( $p \approx 1$ ), Thomson (1998; cited in Sidani\& Gardner, 2000, p. 598) believe that the Lebanese have always placed one foot in the Mediterranean and one foot in the desert'; a concept which is related to openness to western culture and preservation of Arabic traditions. COL in 'Eastern' cultures may emphasize family and humane orientation more than institutionalization, which is reflected in the dominant family business sector and high risks of failure when business is transferred to second or third generation (UNDP, 2011-2012, p. 60).

Dirani (2006) cited Sharabi(1988) arguing that "patriarchal nature of Lebanese culture, where individuals tend to give up their independence and submit to the rule of the father, represents an important factor in how individuals look at work" ( $p$. 88).In a study by Chakour (2001; cited in Ahmad \& Julian, 2012, p. 30), he showed that the Lebanese perceive their country as a place where high value is placed on self-sufficiency, individualism and personal initiative; and,Sayigh(1962; cited in Ahmad \& Julian, 2012, p. 30), suggest that the Lebanese businessman comes out as a 'die-hard' individualist. These pseudo-conflicting views may refer to differentiated cultural concept of dimensions set by other cultures. For example, Robertson et al. (2002, p. 594) concludes that organizational beliefs' correlation to both individualism and humanist beliefs may be unique to the Middle Eastern sample, and the strongly correlated participative and political beliefs could be inherent to the Arabic culture.

$\mathrm{H}_{4}$ : Lebanese societal culture correlates positively with 'power distance'

Table 17 shows that the Lebanese at a mean of (2.39) do not promote PD ( $p \approx 0)$; hence, Hypothesis 4 is not supported. Hierarchy and power differentiation are unlikeable attitudes. People tend to express PD practices cautiously, hoping to 
minimize it by indicating a 'Should be' value, not "As is' fact. Previous findings of Hofstede and GLOBE concluded a high PD among Arab countries (4.73 - 5.80 on 7-Likert scale).

\section{CONCLUSION AND RECOMMENDATIONS}

This study could be one of the first attempts to expand on GLOBE project or Hofstede's work in Lebanon. Results indicate significant issues which are of benefit to managers and educators:

High or low score of a certain cultural factor does not predict clearly enough if the said factor is advantageous or not. Combined interpretation of more than one factor explains better national cultural background. Western findings on PD high scores (see Table 2) indicate lack of initiative and entrepreneurship, which is unobserved within Lebanese society. Though, for example, constructs of COL, FO, PO and PD seem to be negatively correlated, their applications in Lebanon signal a unique culture.

- In Lebanon, PO attained significant support, as noted in the research and reflected in the reality. People prioritize entrepreneurship spirit, which overrides PD and implicitly sums up other factors. This could be useful to influence other cultural factors, diminish their negative patterns, and attract talents.

- In general, the Lebanese enjoy dynamic cultural settings capable of optimal talents' unfolding. Development of performanceculturemay refer to a unique combination of national attitudes. Aim should not be to degrade certain cultural factors, for example COL or PD, as suggested by researchers of different cultures, but to understand how natives perceive the culture as a whole. Does pure individualism unfold more potential and advance societies better? Does authority of society or family lessen initiative spirit? Many other questions like these are difficult to answer separately.

However, this initial exploration of cultural attitudes among Universities' HR paves the way for more researches, guides HR decision makers, and sheds light on assessing educational outcomes.

\section{LIMITATIONS AND FUTURE RESEARCH}

Concern is usually expressed about generalization. First, at the theoretical level, cultural constructs concluded in other cultures are disputable: convergent or divergent,uni- or multidimensional, interpretation in other languages and different societal settings, and measures used. The variances obscure a clear understanding of national culture. Second, at the practical level, researchers do not claim HR at universities represent concisely all Lebanese HR; accordingly, repeating and extending similar investigation of HR cultural attitudes at other sectors is needed. Third, other factors that may have influence during fieldwork period were not considered.

Same cultural constructs may differ from society to another. Individualism and Collectivism are considered to be opposite attitudes (House et al, 2004, p. 464), but it should not be so in all cultures. Further research is needed concerning cultural constructs at national and cross-cultural levels.

However, although few studies have been conducted in Lebanon about the topic (Dirani, 2006; Lahoud, 2008; Sidani\& Gardner, 2000), it is important to note that the findings of the current research are exploratory in nature, and can be used by other researchers, Middle Eastern or others; consequently, cross-cultural comparisons could be performed. Moreover, another contribution of the current study is its stimulating effect that might lead others to further explore the Lebanese cultural dimensions versus the different constituencies of the workforce at large.

\section{ACKNOWLEDGMENTS}

The authors would like to acknowledge the constructive criticism and editing performed by Mrs. Henriette Skaff, senior editor at AUST's Publications Department.

\section{REFERENCES}

[1] Ahmad, Zafar U. \&Julian, Craig C.(2012). International Entrepreneurship in Lebanon, Global Business Review, 13, 25.

[2] Ali, A. J. (1995). Cultural discontinuity and Arab management thought. International Studies of Management \& Organization, 25(3), 7-31.

[3] Armstrong, Michael (2009). Handbook of Human Resource Management Practice. Eleventh ed., London:Kogan Page.

[4] Ashford, Orlando (2014). Talentism: Unlocking the Power of the New Human Ecosystem.Mercer.

[5] Association of Banks of Lebanon (ABL) (2013). The Lebanese Banking Sector: Pillar of Lebanon's stability. Retrieved August 23, 2014, from http://www.abl.org.lb/library/files/ABL\%202013\%20LBS.pdf

[6] Bhawuk, Dharm. P.S. (2003). Culture's influence on creativity: the case of Indian spirituality. International Journal of Intercultural Relations, 27, 1-22.

[7] Bik, Olof (2010). The Behavior of Assurance Professionals: A Cross-cultural Perspective. (PhD Dissertation). UitgeverijEburon. 
[8] BouJaoude, S., \&Abd-El-Khalick, F. (2004). A Decade of Science Education Research in Lebanon (1992-2002): Trends and Issues. In Mutua, K \&Sunal, C. S. (Eds.), (203-241). Research on Education in Africa, the Caribbean, and the Middle East, Vol.1. Greenwich CT: Info Age Press.

[9] Budhwar, Pawan S. \& Khatri, Naresh (2001). A Comparative Study of HR Practices in Britain and India.The International Journal of Human Resource Management, 12(5), 800-826.

[10] Center of Research and Development - CRD (2014). Education Report 2005_Arabic.Retrieved June 1, 2014, from www.cdr.gov.lb.

[11] Central Administration of Statistics (CAS) (2013a). SIF 3: Education in Lebanon. 2012.Retrieved June 1, 2013, from http://www.cas.gov.lb

[12] Central Administration of Statistics (CAS) (2013b). MICS: Clustered Multi-Indicators Survey in Lebanon.2009.Retrieved June 21, 2013, from http://www.cas.gov.lb

[13] Chakour, D.Z. (2001). Entrepreneurship in Lebanon: Situation and informational framework. (MBA Thesis), School of Business, American University of Beirut, Beirut, Lebanon.

[14] Charbaji, Abdulrazzak (2009).The Effect of Globalization on Commitment to Ethical Corporate Governance and Corporate Social Responsibility in Lebanon. Social Responsibility Journal,5(3), 376-387.

[15] Cheng, Brian (2013).Creating A Smarter Workforce by Empowering People and Transforming Business.Presentation of IBM Asean.Retrieved May 19, 2013, from http://ftp.software.ibm.com

[16] CIA (2013).World Factbook.Retrieved June 21, 2013, from https://www.cia.gov/library/publications/download

[17] Dedoussis, E.(2004). A Cross-Cultural Comparison of Organizational Culture: Evidence from Universities in the Arab World and Japan. Cross Cultural Management, 11,1.

[18] Dirani, Khalil (2006).Exploring Socio-cultural Factors That Influence HRD Practices in Lebanon. Human Resource Development International,9(1), 85-98.

[19] Eigenhuis, Ap.\&Dijk, Rob van (2007). High performance business strategy: inspiring success through effective human resource management. London:Kogan Page.

[20] El Jurdi,Amal K. (2010). Modern Management Practices in Administrative Reforms: Case Study of the Lebanese Public Procurement Draft Law.(Unpublished Master Thesis).Beirut: American University of Beirut.

[21] Elsaid, Eahab\&Elsaid,Abdel Moneim(2012). Culture and Leadership: Comparing Egypt to the GLOBE Study of 62 Societies. Business and Management Research 1(2), 1-13.

[22] Field, Andy (2009).Discovering Statistics Using SPSS (Additional Web Material).(3 ${ }^{\text {rd }}$ edition).Sage Publications.

[23] Fox, N., Hunn, A., \&Mathers, N. (2007). Sampling and Sample Size Calculation, The NIHR RDS for the East Midlands / Yorkshire \& the Humber.

[24] Gaillard, Jacques (2010).Measuring Research and Development in Developing Countries: Main Characteristics and Implications for the Frascati Manual. SAGE Publications: Science, Technology \& Society, 15(1), 77-111.

[25] Hair, J., R. Anderson, R. Tatham, and W. Black (1998). Multivariate Data Analysis. Upper Saddle River, NJ: Prentice Hall.

[26] Hejase, H.J., Rifai, R., Tabsh, H., \&Hejase, A.J. (2012). Major Forces Leading to the Shift in the HR Function in Lebanon: An Exploratory Research. British Journal of Humanities and Social Sciences, 7(1), 21-39.

[27] Hejase, A.J. \&Hejase, H.J. (2013). Research Methods: A Practical Approach for Business Students, (2 ${ }^{\text {nd }}$ edition), Philadelphia, PA: Masadir Inc.

[28] Hejase, A.J., Hejase, H.J., \&Hejase, A.H. (2014). Modelling Earning Gaps: An Assessment of the Impact of Sticky Floors and Glass Ceiling in Lebanon. International Review of Management and Business Research,7(1), 431-443.

[29] Hoedemaekers, C. (2008).Performance, Pinned Down: A Lacanian Analysis of Subjectivity at work.(PhD Thesis).Erasmus Universiteit Rotterdam.

[30] Hofstede, G. (1983). National Cultures Revisited. Cross-Cultural Research, 18, 285. Retrieved July 12, 2103, from http://ccr.sagepub.com/cgi.

[31] Hofstede, G. (1984).Culture's Consequences: International Differences in Work-Related Values. ThousandOaks, CA: Sage.

[32] Hofstede, G. (1997). Cultures and Organizations: Software of the Mind, McGraw-Hill.

[33] Hofstede, G. (2001). Culture's Consequences: Comparing Values, Behaviors, Institutions and Organizations across Nations. Sage Publications.

[34] Hofstede, G. (2011).Dimensionalizing Cultures: The Hofstede Model in Context. Online Readings in Psychology and Culture, Unit 2. Retrieved July 12, 2013, from http://scholarworks.gvsu.edu/orpc/vol2/iss1/8 
[35] House, R.J., Hanges, P.J., Javidan, M., Dorfman, P.W. \& Gupta, V. (2004). Culture, Leadership, and Organizations: The GLOBE Study of 62 Societies. California: Sage Publications, Inc.

[36] Hubbard, F.,\&Lin, Y. (2011).Cross-Cultural Survey Guidelines: V. Sample Design.University of Michigan. Retrieved July 23, 2013, fromhttp://www.ccsg.isr.umich.edu/sampling.cfm, retrieved on 21-9-2013.

[37] International Labour Organization (2014). Global Employment Trends 2014.International Labour Office, CH-1211 Geneva 22, Switzerland. Retrieved September 10, 2014, from http://www.ilo.org/wcmsp5/groups/public/--dgreports/---dcomm/---publ/documents/publication/wcms_233953.pdf

[38] Jacobs, E. (2013, December).Principles for Reforming Workforce Development and Human Capital Policies in the United States.Executive Summary.Governance Studies at Brookings.

[39] Kabaskal, H., \&Bodur, M. (2002). Arabic cluster: a bridge between East and West, Journal of World Business, 37, pp. $40-54$

[40] Lahoud, A. L. (2008). The Role of Cultural (Architecture) Factors in Forging Identity. National Identities, 10(4), 389-398.

[41] Lebanese Transparency Association (2011). Promoting Transparency and Enhancing Integrity in the Arab region.National Integrity System Study, Lebanon. Retrieved September 10, 2014, from http://www.transparencylebanon.org/publications/nisennew.pdf

[42] Lee, S. H. (2006).Constructing effective questionnaires. In: J. A. Pershing (Ed.), Handbook of human performance technology (3 $3^{\text {rd }}$ edition) (pp. 760-779). San Francisco: Pfeiffer.

[43] Mankin, D. (2009). Human Resources Development, Oxford University Press. Manpower Group (2013). Talent Shortage Survey Research Results, Milwaukee.

[44] Manpower Group (2013). 2013 Talent Shortage Survey: Research Results. Manpower Group, Milwaukee, Wisconsin USA.

[45] McLean, G.\& McLean, L. (2001). If We Can't Define HRD in One Country, How Can We Define it in an International Context?Human Resource Development International, 4(3), 313-326.

[46] Ministry of Finance (2013). Public Finance Annual Review 2012.Beirut, Republic of Lebanon.

[47] Monavvarian, A.,\&Khamda, Z. (2010). Towards Successful Knowledge Management: People Development Approach.Business Strategy Series, 11(1), 20-42.

[48] Nauffal, Diane (2004).Higher Education in Lebanon: Management Cultures and their Impact on Performance Outcomes.(Ph.D. Thesis). University of Birmingham.

[49] Pei, LB., Xia, J.J., \&Yan, J.L.(2010). Cross-cultural Adaptation, Reliability and Validity of the Chinese Version of the Fear Avoidance Beliefs Questionnaire. The Journal of International Medical Research, 38, 1985 - 1996.

[50] Ralston, David A., Egri, Carolyn P., Riddle, Liesl, Butt, Arif, Dalgic, Tevfik, \& Brock, David M. (2012). Managerial values in the greater Middle East: Similarities and differences across seven countries. International Business Review, 21, $480-492$.

[51] Rattray, J.C., \&Jones, M.C. (2007). Essential Elements of Questionnaire Design and Development, Journal of Clinical Nursing, 16, 234-243.

[52] Robertson, C. J., Al-Khatib, J. A., Al-Habib, M., \&Lanoue, D. (2001). Beliefs about work in the Middle East and the convergence versus divergence of values. Journal ofWorld Business, 36(3), 223-244.

[53] Robertson, C.J., Al-Khatib, J.A., \& Al-Habib, Mohammed (2002). The Relationship between Arab Values and Work Beliefs: An Exploratory Examination. Thunderbird International Business Review, 44(5) 583-601.

[54] Ronen, S., \&Shenkar, O. (1985). Clustering countries on attitudinal dimensions: A review and synthesis. Academy of Management Review, 10(3), 435-454.

[55] Runco, M. A.,\&Pritzker, S. (2011). (Eds.). Encyclopedia of creativity. Oxford:Elsevier,(2 ${ }^{\text {nd }}$ edition), 2, 533-538.

[56] Sayigh, Y.A. (1962). Entrepreneurs of Lebanon: The role of the business leader in a developing economy. Cambridge, MA: Harvard Business Press.

[57] Sharma, P.(2010). Measuring Personal Cultural Orientations: Scale Development And Validation.Journal of the Academy of Marketing Science, 38, 787-806.

[58] Sidani, Y. (2005). Women, work, and Islam in Arab societies, Women in Management Review 20(7), 498-512.

[59] Sidani, Y.M.,\&Gardner, W.L.(2000). Work Values Among Lebanese Workers. The Journal of Social Psychology, 140(5), 597-607.

[60] Simonton, D.K. (2003a). Creative cultures, nations and civilizations: Strategies and results. In P.B. Paulus \& B.A Nijstad (Eds.). Group creativity: Innovation through collaboration (pp. 304-328). New York: Oxford University Press. 
[61]The Lebanese Center for Policy Studies - LCPS (1999). The Arab World and Globalization: Challenges and Opportunities. Arab Forum Conference, Tunisia, November 30 and December 2, 1999.

[62] Tlaiss, H.,\&Kauser, S.(2010). Perceived Organizational Barriers to Women's Career Advancement in Lebanon. Gender in Management: An International Journal,25(6), 462-496.

[63] UNDP (2011-2012). Globalization: Towards a Lebanese Agenda: 2011-2012. Retrieved June 21, 2013, from http://www.arab-hdr.org/publications/other/undp/hdr/2002/lebanon-e.pdf

[64] UNDP (2013). Human Development Report 2013: The Rise of the South: Human Progress in a Diverse World. Retrieved August 12, 2013, from http://hdr.undp.org.

[65] World Economic Forum (2013a). The Global Competitiveness Report 2012-2013.Retrieved June 21, 2013, from http://www.weforum.org/gcr.

[66] World Economic Forum. (2013b). The Human Capital Report, 2013. Prepared in collaboration with Mercer.Retrieved May 20, 2013, from http://www3. weforum.org/docs/WEF_HumanCapitalReport_2013.pdf

[67] Yordanova, GK. (2011).Managing With Cultural Intelligence.(PhD Dissertation).Denmark: Aahrus University.

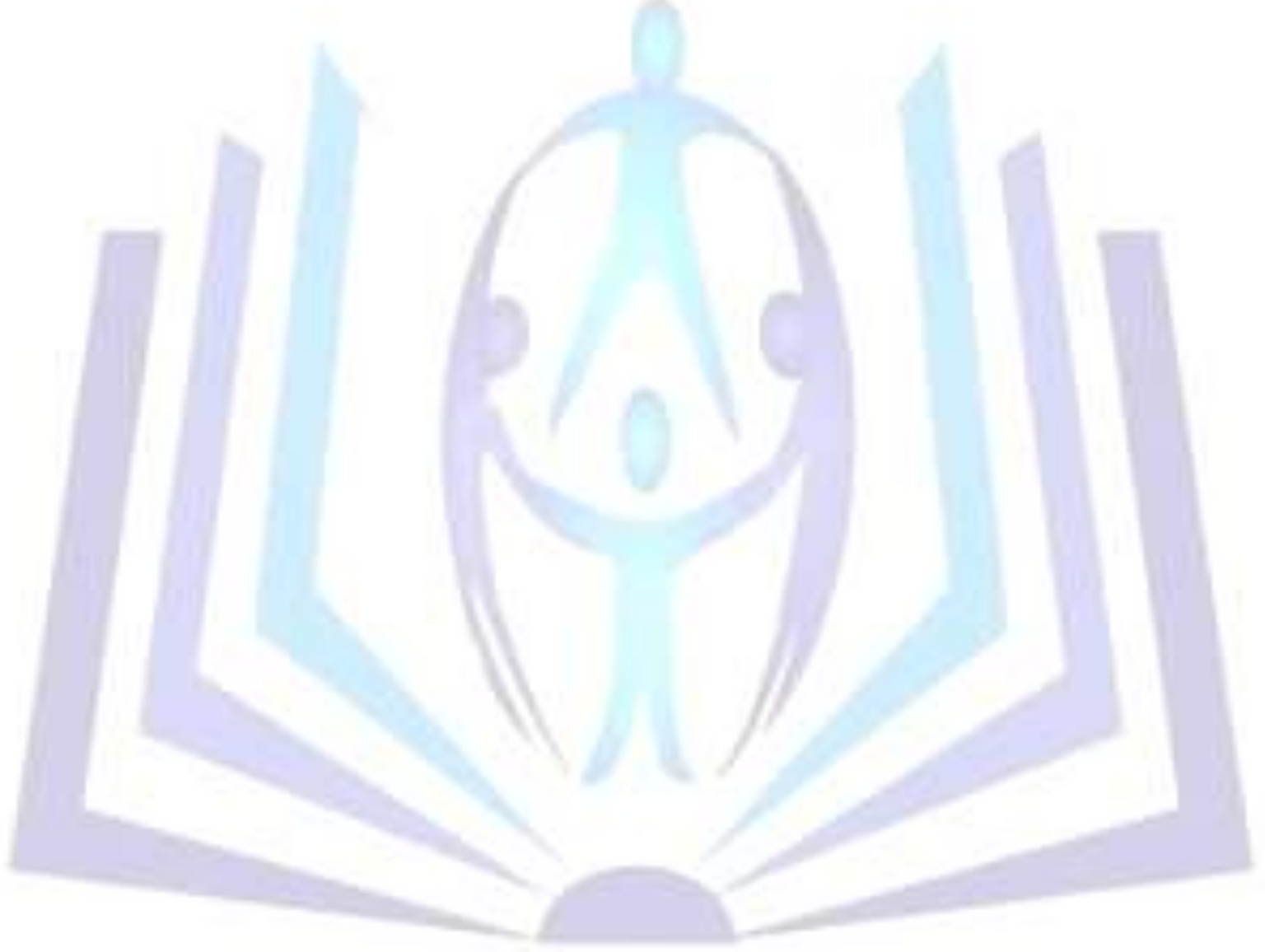

